\title{
Job Stress and Burnout: Occupational Hazards for Services Staff
}

\begin{abstract}
Occupational hazards of stress are noted in individuals designated with responsibilities for service delivery in academic libraries. Staff members who perform duties requiring direct service to the library user are expressing concern about negative characteristics of job stress and the nonproductive results of burnout. Three components contributing to negative characteristics are highlighted as sources of frustration for services staff. The components are the individual ability to handle a stressful occupation, traditional organization structure, and fragmented professional support. Solutions are discussed in terms of productive individual coping strategies, enhanced organizational design, and cohesive professional support.
\end{abstract}

A representing large academic libraries provided a forum to exchange ideas and laments. ${ }^{1}$ Repeatedly voiced during the discussion was a level of frustration directed at the job demands of the reference environment in libraries serving a large student and faculty complement. Although the nature of the exchange permitted only superficial analysis of the real problems, the recurring theme was the concern for stress and burnout brought about by an increasing demand for services. The meeting brought attention to the dilemma of service professionals, specifically library reference staffs, trying to preserve quality service and staff stability while dealing with the occupational hazards of job stress and burnout. Burnout itself has many negative implications, often resulting in loss of highly qualified staff to other lines of work or nonproductive coping strategies such as loss of initiative, energy, or maximizing aptitude. ${ }^{2}$

Sandra H. Neville is assistant director for interpretative services, University Libraries, University of Georgia, Athens.
Job stress involves three major issues. The first is the ability of the individual to handle a stressful occupation. The individual's ability to cope with the frustration of job stress immediately raises other questions. Does recruitment literature adequately emphasize the stressful nature of the work? Do individuals seeking public service positions demonstrate the necessary energy, decision-making ability, intellectual curiosity, and communication skills necessary to meet the vigorous performance requirements?

Once the recruitment and hiring of the individual is completed, a relationship between the individual and the organization evolves that directly influences the stressful nature of the job. A second issue related to job stress is the pattern of influences between the individual and the organization, because the organization plays a significant role in preparing an appropriate environment for service delivery. Increasingly it is argued that libraries are shifting priorities from an emphasis on material orientation to a client orientation. ${ }^{3}$ As a result of the shift, libraries are moving away from materialsoriented concepts of quantifying biblio- 
graphic units and instead are placing greater value on assessments of service quality. The academic library is becoming increasingly accountable for delivering information and document services, thereby placing greater demands on the staff members responsible for direct services, who then must assure the success of the emerging library priority. However, the library does not articulate its client orientation through its structure, which creates organizational ambiguities and an inappropriate environment for service delivery. In spite of this shift in emphasis, many academic libraries will continue to use a structure that reinforces a materials orientation, where priorities are placed on preservation, acquisition, and storage of materials. ${ }^{4}$

A third issue suggests that the professional support provided for direct services is fragmented and multidirectional. Activities sponsored by national associations tend to reinforce the material orientation described earlier. This can be observed in cohesive association support for traditional technical operation areas when compared with the numerous multidirectional groups representing direct-service interests. A lack of synthesis in professional support reflects the ambiguity of organizational priorities at a time when strong professional support is essential.

In elaborating on these three issues, the following discussion will cover the individual's ability to cope with job stress and the role of the organization structure in providing a supportive environment for direct services. A final comment will address concerns about professional association support.

\section{INDIVIDUAL ABILITIES AND COPING STRATEGIES}

The ability of the individual to handle a stressful occupation has received little attention in the literature of librarianship. Librarians rarely note that many service jobs have inherently high risk and stressful conditions. A review of library literature disclosed few references on the topic of job stress, and these tended to concentrate on physical working conditions rather than individual coping strategies. In contrast, management and administration literature contained numerous references to the general problem of job stress and individual coping strategies.

Stressful job situations are characterized by the individual's perception of unwanted outcomes, the amount of evaluation, the evaluator's capability to judge performance, time separation between performance and occurrence of outcomes, task difficulty, and uncertainty of success. ${ }^{5}$ The aspects that can be identified as contributing to the stressful nature of direct-service responsibilities also might include some specific elements such as unrealistic deadlines, the problem of expectations not matching the reality of the job, the political atmosphere of the organization, and a lack of feedback as duties are performed.

The management literature frequently discussed topics concerned with the personality package of the individual as an important part of job stress. The characteristics of a stressful job situation as outlined above must be weighed against the personality of the individual who holds the position. Any situation can produce stress and the individual must have an ability to cope with frustration. Personality factors or stressors are an important determinant of individual coping ability. ${ }^{6}$ Stressors are variables such as lack of meaning in the job, frustrated ambition, obsessive concern for work, level of anxiety,. level of emotionality, and tolerance for ambiguity. Every individual brings to the job a package of stressors, and the distribution or degree of intensity of each determines the ability to cope with stressful conditions.

Although personality stressors and characteristics of stressful occupations are infrequently discussed in the library literature, a professional recognition of job stress problems is evident in the number of middlemanager training programs offered for librarians at state and national meetings. The training programs usually concentrate on time-management techniques and job enrichment processes. These techniques can help the individual overcome some conditions of job stress. Certainly efforts at job enrichment training help the individual determine the work-related elements of tasks and procedures flow that might assure greater satisfaction. ${ }^{7}$ The opportunity to analyze cooperation between work units and job de- 


\section{4 / College \& Research Libraries • May 1981}

sign can contribute to individual satisfaction. Time-management techniques can relieve some strain by providing the individual with tools that can be applied immediately to daily work situations.

However, permanent solutions to stress may not result from the application of individual approaches or strategies. After an initial effort to apply individual strategies, many librarians may sense a lack of success, which can contribute more rapidly to the most counterproductive condition, referred to as burnout. At this point, a staff member either leaves or finds methods to become a survivor only, a deadweight in the organization. In fact, the very techniques that provide the individual with a level of objectivity on a management predicament may contribute to increased frustration, which in turn is complicated by the unbending and traditional design of the organization structure.

Newman and Beehr, writing in support of this prediction, observe that there are many strategies suggested for handling individual job stress, but unfortunately no evaluation of effectiveness for these strategies has been demonstrated. They point to the need to recognize the fact that multiple causation and multiple effects require the use of combinations of personal strategies and organizational strategies. ${ }^{8}$

A study of job stress directed to a specific line of work (trade salesperson) found that individual nonproductive anxiety and stress were reduced when a certain type of organization structure was in use. In this particular case, a "flat" organization structure (i.e., few hierarchical levels) was found to be conducive to higher productivity and greater job satisfaction than other types, described as medium or tall structures. ${ }^{9}$ This should not be construed as a recommendation for flat structures; instead it should be recognized as an effort to marry the type of job activity with an appropriate supporting organizational structure to achieve maximum benefit for both the individual and the institution.

The specific example above can be conceptualized as positively combining the dimensions of individual tension, influence, and satisfaction with the moderating effects of institutional structure, organizational member characteristics, and the external environment of the organization. ${ }^{10}$ In these terms, the dimension of individual tension is moderated by the decision-unit structure of the institution; the dimension of personal influence is moderated by the characteristics that the individual provides as an organization member; and the dimension of satisfaction is moderated by the external environment of the organization. The academic library has an institution of higher learning as its external environment, as well as relationships with professionals in state, regional, and national settings. As a point of further emphasis, the dimension of individual tension, according to the conceptual model, is influenced by the organization structure or the decision-unit structure.

In examining the problems of individual tension and role stress in organizations using complex technology, a group of researchers noted the complicated web of interdependencies and observed that factors that reduce stress for one employee may increase it for another. ${ }^{11}$ They concluded:

We can no longer ignore the fact that individuals do not perform tasks in isolation. We must extend our analyses to others in the organization and the context in which they and the subjects of our inquiries operate. ${ }^{12}$

\section{ORGANIZATION STRUCTURE}

The issue of the individual's ability to cope is so closely related to characteristics of the organization structure that a confusion of the two issues easily develops. Sources of stress can be associated with different functional activities and with the level of ambiguity within the organization.

It is possible that the structure of the organization contributes to conditions of stress and burnout found among many staff members responsible for direct services. Inappropriate organization structure in libraries may result from a shift in library priorities to a client orientation and calls for a process of organizational review. A review of work units within the library might well take advantage of a classification of user functions as mentioned by F. W. Lancaster. He brings a fresh viewpoint to the structure of service delivery responsibilities by indicating six categories of user functions:

I. Document Services-providing documents for 
which user has current bibliographic descriptions (citations)

II. Citation Services-providing citations to documents, including verification and subject bibliographies

III. Answer Services-providing specific information to answer user's questions

IV. Work-Space Services-providing space equipped for user to work within library

V. Instruction and Consultation Services

VI. Adjunct Services ${ }^{13}$

By looking at the organization structure through the user-function categories, directservice departments can review the placement of service responsibilities and determine obstacles to service delivery. Traditionally, responsibilities were assigned to organizational units based on concepts of like procedures or similarity of processes, putting like tasks together with a strong emphasis on differentiation, repression, and stability. ${ }^{14}$ A preferred placing of responsibilities for the direct services must respect the flow of work and all the related activities necessary for the successful completion of the requested service. In this manner, departments would be responsible for related activities whether they are "like" or "unlike" as tasks. Emphasis here is on integration, wriggle room, change, and flow of work. ${ }^{15}$

Applying the user-function categories as an approach to organizational review offers an opportunity to examine the library structure from the client-oriented viewpoint. In the past two decades, many academic libraries have determined the work-flow design by the demands of the material-oriented functions. When this is the case, feedback mechanisms do not communicate smoothly to staff responsible for direct-service functions; units and departments responsible for service delivery are at the end of the flow, with few communication vehicles along the way. Evidence of nonsupportive organizational structure is most notable when the achievement of even minor service goals requires the involvement of several departments and is accompanied by a complicated tangle of paperwork and employee resistance.

Organizational structures that conflict with changing goals force a type of administration called crisis management. Many librarians responsible for managing service departments may feel the stress and frustration of dealing with problems on a crisis basis. Regardless of the individual's management training, the organization forces the individual to use this uncomfortable type of management because work flow and feedback mechanisms fail to support the service goals. When the line function of the organization serves a material orientation rather than a client orientation, management by crisis may result; "in spite of ever more sophisticated tools for management, an uncommonly large number of organizations continue to be run in primitive manner." 16

The efforts to treat the symptoms of stress may not be remedied by individual training in stress management, time management, and job enrichment techniques. Although the current attempts to concentrate on the individual approach for coping strategies are useful, dependence on individual solutions to stress problems for services staff may not be satisfactory in the long run. Studying the organization structure in relation to the user-function categories is essential and will offer a productive method for diagnosing the real occupational hazards of direct-services staff.

A review of organization structures in academic libraries can provide more meaningful support if results of such review projects are shared among the institutions through the avenues opened by professional associations. Professional associations can offer an important link in the review process by augmenting desirable outcomes during this period of shifting priorities.

\section{PROFESSIONAL SUPPORT}

Academic libraries have completed several decades of placing the highest priority on collection building, preservation, and storage as primary activities supporting a materials orientation. Evidence of this emphasis is readily observed in professionalassociation support. For example, the annual statistical report issued by the Association of Research Libraries (ARL) provides compilations that reinforce the materials orientation. ${ }^{17}$ In the ARL Statistics, the data gathered (i.e., collection size, materials budget, volumes processed, etc.) represent quantities that serve the needs of the traditional activities. 
In assessing direct-service support from the ARL Statistics, the interlibrary loan data may have become the one exception to the comments concerning the bias toward a materials orientation. This item was originally included, no doubt, as a measure of collection building within the institution. However, the uses of interlibrary loan have changed as institutions adapt to more resource-sharing techniques, and now the figures presented can be considered reflections of service commitments. As relationships with networks evolve and cooperative agreements in a variety of geographical configurations are made, interlibrary loan data have become more of a measure of service strength and less that of collection strength.

While the library organization responded to the pressures of a material orientation, measures of internal efficiency in technical services became a frequent topic of examination in the professional literature. ${ }^{18}$ The attempts to quantify library goals through analysis of technical operations have limitations, however, partly due to the carelessly defined sources of data and lack of standards for cost measurements. Efficiency studies reported in the literature were not transportable because of these limitations and could not be generalized to other applications. To compound our problem, typical technical operations studies made no attempt to assess the effect of the internal operation on the public-services or user-function operations. ${ }^{19}$ The impact of efficiency on direct-service effectiveness was ignored or excluded by the narrow definitions of technical operations. The quantifier found the client orientation less attractive, perhaps because of the more elusive qualitative environment or the low priority of services as an organizational goal. The derivation of useful direct-service assessments has eluded the skills of the "hypereconomist," to borrow a term. ${ }^{20}$

The need for good assessment devices of a statistical nature should be addressed through the cohesive support of professional library associations. Units or divisions that address the issues of user functions are numerous and fragmented in the American Library Association. An example of the lack of cohesiveness is apparent when the var- ious committees dealing with direct-service interests are observed in the Library Administration and Management Association (LAMA), the Reference and Adult Services Division (RASD), and the Association of College and Research Libraries (ACRL), to name a few. This should be compared with the fact that a division that represents the interests of technical-service concerns has been in existence for some time.

Recently, RASD submitted a revision in its bylaws designed to address an aspect of this need. The revision to the bylaws as proposed (Article II, Section 1) states that the objectives of the division should include a group responsible for the synthesis of activities in all units of the American Library Association where direct service to the library user is involved. ${ }^{21}$ The emphasis on synthesis where concerns for the user functions are involved is an important step to a cohesive approach in dealing with directservice needs. The type of library is recommended as a criterion for consideration in the RASD-proposed change. Following the example of RASD, colleges and universities might find it useful to establish an activity as part of their association, and enhance the role of ACRL in supporting the functions responsible for service delivery.

\section{SUMMARY}

Professional librarians responsible for the direct-service functions are frequently faced with the occupational hazards of job stress and burnout, which are nonproductive outcomes of organizational shifts in priorities. Training the individual to develop personal strategies to cope with stress by improving management skills will provide a temporary reprieve from certain aspects of job frustration, but a review of organizational design can offer more permanent solutions to a problem that taxes both the individual and the institution.

Library organizations and professional associations can create environments that will help or hinder effectiveness, facilitate or inhibit service activities. Libraries in the next decade must recognize the shift from a materials orientation to a client orientation and design the organization structure to serve the work flow of library services. Associations and other professional groups 
must address the direct-service functions as a cohesive activity deserving more than fragmented attention. Only then will nonproductive, stressful conditions contributing to services-staff frustration and burnout be changed to productive conditions in an organization environment supporting directservice responsibilities and objectives.

\section{REFERENCES}

1. Meeting of Heads of Reference Departments in Large Academic Libraries, American Library Association Midwinter Meeting, Chicago, January 22, 1980.

2. Albert O. Hirschman, Exit, Voice, and Loyalty: Responses to Decline in Firms, Organizations, and States (Cambridge, Mass., Harvard Univ. Pr., 1970), p.1.

3. Thomas J. Galvin, “Access, Analysis, Accountability: Three Dimensions of the ClientOriented Society" (Lecture presented at Louisiana State University, Graduate School of Library Science, Library Lecture Series, October 13, 1977).

4. Doralyn J. Hickey, "Public and Technical Services: A Revised Relationship," in Norman D. Stevens, ed., Essays for Ralph Shaw (Metuchen, N.J.: Scarecrow, 1975), p.183.

5. Bruce M. Meglino, "Stress and Performance: Are They Always Compatible?" Supervisory Management 22:2-12 (March 1979).

6. Jere E. Yates, Managing Stress (New York: AMACON, 1979), p.60-64. A list of symptoms for stress-prone behavior can be found on page 67 in this book.

7. Lyle Yorks, Job Enrichment Revisited (New York: AMACON, 1979), p.13.

8 John E. Newman and Terry A. Beehr, "Personal and Organizational Strategies for Handling Job Stress; a Review of Research and Opinion," Personnel Psychology 32:1-43 (Summer 1979).

9. John M. Ivancevich and James H. Donnelly, Jr., "Relation of Organizational Structure to Job Satisfaction, Anxiety-Stress, and Performance,"-Administrative Science Quarterly 20:272-80 (June 1975).

- 10. Michael J. O'Connell and L. L. Cummings, "The Moderating Effects of Environment and Structure on the Satisfaction-Tension-Influ- ence Network," Organizational Behavior and Human Performance 17:351-66 (Dec. 1976).

11. Michael K. Moch, Jean Bartunek, and Daniel J. Brass, "Structure, Task Characteristics, and Experienced Role Stress in Organizations Employing Complex Technology," Organizational Behavior and Human Performance 24:258-68 (Oct. 1979).

12. Ibid., p. 267.

13. Frederick W. Lancaster, The Measurement and Evaluation of Library Services (Washington, D.C.: Information Resources Pr., 1977), p.241.

14. Robert T. Golembiewski, "Organization Patterns of the Future: What They Mean to Personnel Administration," in Robert A. Zawacki and D. D. Warrick, eds., Organization Development: Managing Change in the Public Sector (Chicago: International Personnel Management Association, 1976), p.277, 279.

15. Ibid., p.276. The apt phrase wriggle room, used by Golembiewski, is defined as "minimum constraints consistent with quality performance."

16. Jim Summers, "Management by Crisis," Public Personnel Management 6:194-200 (May/ June 1977).

17. ARL Statistics (Washington, D.C.: Association of Research Libraries, annual).

18. Lancaster, Measurement and Evaluation, p. 265 .

19. Ibid., p. 269.

20. Maurice B. Line, "The Psychopathology of Uneconomics," Library Trends 28:107-19 (Summer 1979). The hypereconomist personifies the tradition of excessive attention to quantifying the efficiency of isolated internal operations.

21. "Notes from RASD Headquarters," $R Q$ 19:9 (Fall 1979). 


\section{Energy \\ information explosion! \\ Energy Abstracts... meeting the challenge}

The continuing energy crisis has created a secondary crisis in the assimilation of related technical information. The sheer volume of new technological information on energy being published in journals, through seminars, conferences, and academic activity around the world makes it impossible for any individual and most libraries to keep fully up to date in this critical field.

Now the Engineering Index, a non-profit organization serving the informational needs of the engineering community for nearly a century, has developed The Engineering Index ENERGY ABSTRACTS, a monthly publication series indexing and abstracting significant worldwide information from diverse energy-related scientific and technological fields.

ENERGY ABSTRACTS is a multidisciplinary publication designed to serve the information seeker involved with fields like Energy Sources, Production, Transmission, Distribution, Utilization, Conservation and Conversion.

To assemble the Engineering Index data base, published information from thousands of sources is carefully read, and abstracts (concise, accurate summaries of consequential material) are generated. Bibliographic citations are provided, making it easy to obtain the full text if required. Copies of most original texts can be obtained through the Engineering Societies Library in New York. The abstracts are indexed, and those related to energy are published separately in monthly, paperbound volumes which provide ease of access and study.

ENERGY ABSTRACTS' utility is enhanced by the addition of energy-related material from several external data base sources, making it the most comprehensive engineering abstracting and indexing single-source service in the marketplace.

ENERGY ABSTRACTS publication is also available in computer-processable form, offering flexible computersearch capability coupled with rapid, in-depth automatic retrieval.

With the Engineering Index ENERGY ABSTRACTS, you can meet the growing need for energy-related engineering information at an economical cost. It belongs in your library.

ENERGY ABSTRACTS 1981 (published monthly): \$375.00 (U.S., Canada, Mexico); $\$ 415.00$ (foreign).

For complete information write or telephone:

Engineering Index, Inc.

345 East 47 th Street

New York, New York 10017

212/644-7615
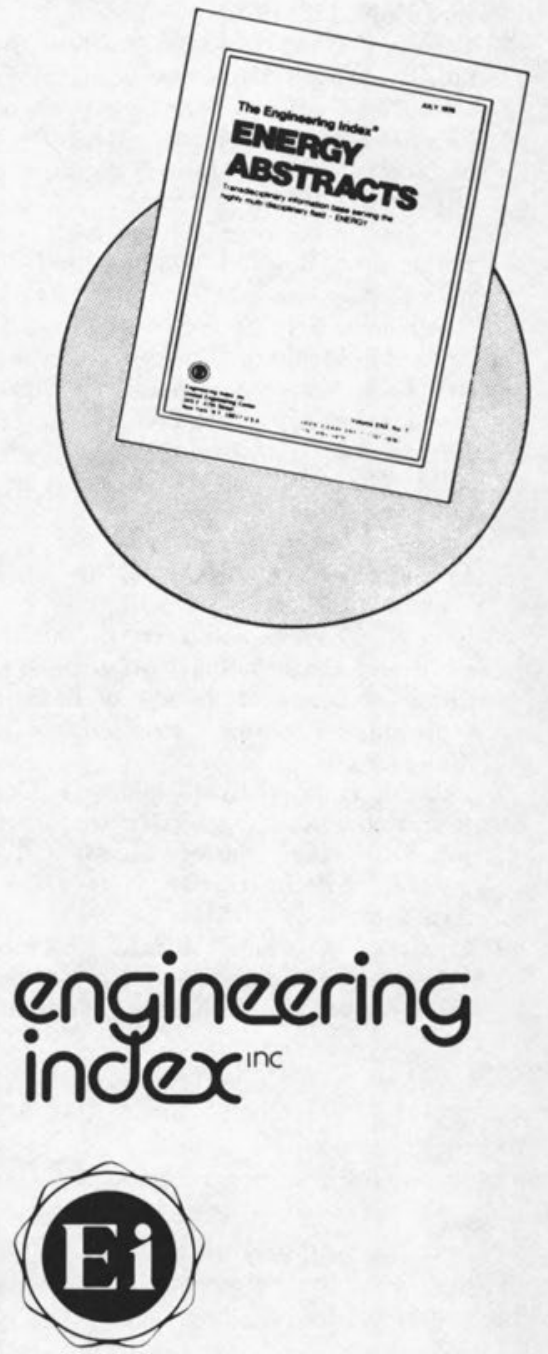